\title{
Green Milk From Contented Cows: Is It Possible?
}

\section{John Webster* \\ Department of Clinical Veterinary Science, University of Bristol, Bristol, United Kingdom}

The dairy industry is open to criticism on several fronts: obesity and ill health among the affluent, high demand for crops that could be consumed more sustainably and more equitably by ourselves, environmental damage and climate change, and abuse of animal welfare through production diseases and denial of normal patterns of behaviour. All these criticisms are valid. It is necessary therefore to examine in depth the nature and extent of specific problems to see which, if any, are inevitable, which can be mitigated and which can be avoided altogether. Dairy cattle, like all ruminants, can be sustained wholly, or in part on complementary feeds; grasses and crop residues that cannot be fed directly to humans. Fed appropriate diets dairy cows can produce more energy and protein for human consumption than they consume. The greenhouse gas, methane is an inevitable consequence of rumen fermentation. High yielding cows in confinement produce less methane per litre of milk. There is some scope for reducing methane production through manipulation of rumen fermentation but the impact is likely to be small. The most serious welfare abuses can be linked to genetic and management strategies designed to maximise milk yield from individual cows. These manifest in production diseases and metabolic exhaustion, both leading to premature culling. All these problems; too much milk, too much food waste, too much methane, too many stressed cows, are matters of degree. The poison is in the dose. Thus, solutions will not come from radical advances in biological science but public and political exercises in moderation.

\section{Keywords: Livestock's Long Shadow, greenhouse gases, emergy analysis, genetic selection, welfare}

Give a man enough to eat, he has many problems, give him not enough to eat, he has only one problem.

- John Webster

\section{MILK PRODUCTION IN THE CONTEXT OF THE GLOBAL DEMAND FOR FOOD}

The essential needs of humans and all animals for the right amount of the right sort of food are immediate, continuous, and have long term consequences for the quality of our lives and that of the planet. Those with too little to eat are unable to promote normal development and good health for themselves and their offspring. Those who eat too much accelerate their rate of decay. The Food and Agriculture Organisation (FAO) (2006) states that $9 \%$ of the world population ( 820 million people) are experiencing severe hunger, two billion (22\%) experience moderate to severe food insecurity [Food and Agriculture Organisation (FAO), 2020]. More than 20\% of children under five show stunted growth. At the same time $13 \%$ are described as moderately to severely obese. Furthermore, things are getting worse at both ends of the scale. 
Increasing numbers of humans self-evidently increases demand for food and puts increasing strain on the capacity of the living environment to meet this demand. However, population numbers per se present less of a strain on resources than increased demand from those with money to spend on attractive but environmentally spendthrift sources of food, especially that from animals given food that we could have eaten ourselves. It has been calculated that if the Chinese consumed the same amounts of the same sort of food as eaten by citizens of the USA (as is their right) they would exhaust the resources of the planet in $<30$ years. Radical change in the way we produce, distribute, and consume food, especially food from animals, is not just a moral aspiration; it is an ecological necessity.

It is self-evident that food from animals puts a greater demand on resources than food from plants, since so much of that food is required to maintain the animals themselves. This simple conclusion has laid the foundations for a number of complex analyses of resource use such as "Livestock's Long Shadow" [Food and Agriculture Organisation (FAO), 2006]. These describe the relative inefficiencies of using animals to exploit resources of sun, soil and water to produce food for human consumption, the degradation of these resources through overuse, the pollution of land and water from excessive waste products and the threat to the climate from greenhouse gases, especially methane from ruminants, which has $\sim 20$ times the global warming potential of carbon dioxide.

Public criticism of the scale and practise of current methods of farming animals for food is based on the following four premises.

- Most of those who can, consume too much meat and milk.

- Food that we could eat is fed to animals while the poor go hungry.

- Livestock's long shadow is destroying the planet.

- Intensive livestock production is incompatible with animal welfare.

\section{THE DAIRY INDUSTRY}

This paper considers the dairy industry, which has become a major target for criticism on all four counts. Given the current state of the industry, much of this criticism is justified. However, it was not ever thus and there are sound reasons why it need not be so in the future. As a child at school, I got free milk, not always a treat on a summer's day after it had sat for some hours in the sun. This policy was a consequence of the classic work of Sir John Boyd Orr in the 1920s who demonstrated that much of the differences among children in both growth and educational attainment could be resolved by improved provision of essential nutrients provided by milk. For most of us today milk per se has become just a commodity, cheaper to buy than some brands of bottled water. The expansion of the dairy industry has been driven largely by the increase in demand for luxury foods, butter, cream, and a huge variety of ice creams, yoghourts, and cheeses. These luxuries are acceptable to lactovegetarians because they don't directly involve the killing of animals.
All this is very recent history. For most of recorded history, getting enough to eat was a struggle for survival and the cow was a highly valued partner in this struggle. The traditional role of the family cow was to provide milk, work, fertiliser, fuel, clothing, and the occasional fatted calf for special occasions, while sustained by fibrous feeds that the family could not digest for themselves, usually from land that the family did not own. She was not competing with the family for food; she was an essential contributor to the harvest. The modern dairy cow, typified by the Holstein breed, is a very different creature: bred, fed, and managed to produce as much milk as possible within intensive, highly mechanised dairy units. Meat production has become a relatively minor consideration, with male calves destined for beef or veal sent, more often than not, off farm to other specialist rearing units. Other traditional roles for the family cow have disappeared altogether. The modern Holstein is most unlikely to be harnessed to a plough! However, while the high yielding cow, confined in a barn, has become the norm for much of the urbanised, affluent human population, the proportion of cows kept in such intensive conditions in the less developed nations is relatively low.

Table 1 [Compassion in World Farming (CIWF), 2020] provides an illustration of the range of cow numbers and milk yields in different regions of the worlds. The highest yields are recorded in USA, Israel, and Saudi Arabia, in the latter two nations, especially, demand is high but the land and climate are entirely alien to the concept of milk from pasture. The EU embraces a range of production systems from the highly intensive in (e.g.) Denmark and the Netherlands to pastoral systems in Ireland and much of Eastern Europe. Here average annual milk yield is 5,900 1 (range: Denmark $-8,4001$, Bulgaria 1,850 l). New Zealand is included in Table 1 as an example of an advanced industry producing milk primarily from grass. Average annual milk yield from the world population of 264 million dairy cows is only $2,270 \mathrm{l}$. The first message to be drawn from this table is that the dairy industry, unlike for example the broiler chicken industry, cannot be viewed, criticized, or applauded as a single homogenous system. The second message is that the dairy cow is a creature of infinite variety that can adapt to a wide range of husbandry methods. This creates the potential to adopt a constructive approach to all four of the concerns outlined above.

The four charges on which the dairy industry stands accused: unhealthy, unfair, unsustainable, and unkind, are not without substance. However, they are (obviously) simplistic because they do not begin to address all the variables in a complex industry. I shall not attempt to rebut these accusations but address them objectively and explore possible pathways to greener, kinder solutions.

\section{AN UNHEALTHY DAIRY INDUSTRY? MOST OF THOSE WHO CAN, CONSUME TOO MUCH MEAT AND MILK}

This has to be the biggest concern because it involves decisions faced by all humans as potential consumers, as against the shrinking minority who are directly concerned with the 
TABLE 1 | Total milk production (million tonnes), cow numbers (millions), and average milk yields of cows (litres per cow per year).

\begin{tabular}{lccc}
\hline & $\begin{array}{c}\text { Total milk production } \\
\text { (million tonnes) }\end{array}$ & $\begin{array}{c}\text { Cow numbers } \\
\text { (millions) }\end{array}$ & $\begin{array}{c}\text { Average milk } \\
\text { yields (litres/cow } \\
\text { year) }\end{array}$ \\
\hline USA & 87. & 9.1 & 9,600 \\
European Union & 135.5 & 23.0 & 5,900 \\
India & 50.3 & 43.6 & 1,150 \\
New Zealand & 17.0 & 4.6 & 3,700 \\
World & 599.4 & 264.4 & 2,270 \\
\hline
\end{tabular}

production of food from animals. For the purposes of analysis, we need to distinguish three distinct concerns: the impact on our own health and welfare, on the health and welfare of the farmed animals and on that of the living environment. The first concern; that of human health and welfare, is largely outside the scope of this paper. However, it is important to view it not only through the eyes of those of us whose income and eating habits may be ranked as adequate to excessive, while approximately one quarter of the world population is chronically or intermittently short of food [Food and Agriculture Organisation (FAO), 2020]. A larger number can get enough to eat but are likely to experience malnutrition because their diet is dominated by starchy grains and roots. For these people, especially child-bearing mothers and their children, foods of animal origin, rich in protein, fats, minerals, and vitamins, are critically important (if not strictly essential) to health and well-being. Milk and eggs appeal to vegetarians because they do not involve killing the animal to get at the food. In a more biological context, milk and (unfertilised) eggs cannot be defined as bits of animals, but simply as foods of the highest nutritional value: the former to feed the growing calf from the time of its birth, the latter to feed the fertilised embryo up to the time of hatching.

The risks to human health of overindulgence in rich foods of animal origin have been researched and documented at great length but they are out with the scope of this paper. For practical purposes the sum of knowledge as to human nutrition may be condensed to eight syllables: "eat food, not too much, mostly plants" (Pollan, 2008).

\section{AN UNFAIR DAIRY INDUSTRY? FOOD THAT WE COULD EAT IS FED TO ANIMALS WHILE THE POOR GO HUNGRY}

This is more than an expression of concern; it is a fact: but it is not an inevitability. When considered in nutritional and ecological terms, the costs and benefits of food from animals are governed by the extent to which they may or may not compete with us for resources. The greatest of the essential demands of animals on resources is for energy from food to fuel the processes of life. This is best described in terms of Metabolizable Energy (ME MJ/kg dry matter) since this defines the amount of fuel that can be extracted from the diet by the processes of digestion and metabolism. In an adult animal in energy balance, neither gaining nor losing weight, all $\mathrm{ME}$ is used for maintenance and converted into heat. ME consumed in excess of maintenance is retained in the body as protein and fat or, in a lactating animal, secreted as milk. Food production from animals is inevitably less efficient than that from plants because much of the food eaten by animals is required to meet their own needs. At maintenance, the gross efficiency of conversion of animal feed into food for human consumption is zero. The net efficiency of conversion of increments of ME fed above maintenance may range from $\sim 0.6$ to 0.8 . The overall gross efficiency of conversion of energy in animal feed to energy in animal product (meat, milk, or eggs) increases with increasing ME intake to a limit set by physiological constrains on appetite. The limit to appetite in highly productive farm animals grown for meat is about three times maintenance and gross efficiency of conversion about 0.3 . High yielding dairy cows may consume ME at 5 times maintenance and achieve a gross efficiency of 0.5 . For further explanation see Webster (2016).

Table 2 compares the efficiency of conversion of feed energy (ME) and protein into hens' eggs, cows' milk, pork meat from the offspring of sows giving birth to 22 piglets/year and beef from extensively reared cow-calf systems where the contribution of the breeding beef cow is one calf/year plus her own carcass at eventual slaughter. In each column the efficiency of conversion of feed energy and protein is expressed in two ways:

- Overall efficiency: food energy and protein (for human consumption) relative to total $\mathrm{ME}$ and protein consumed by the productive and support animals. For meat animals these correspond to the slaughter and breeding generations. For the dairy industry they correspond to the lactating adults and replacement heifers.

- Competitive efficiency: food energy and protein (for human consumption) relative to animal consumption of $\mathrm{ME}$ and protein from "competitive" feed sources (i.e., feeds such as cereals that could have been fed directly to humans) as distinct from "complementary" feeds (grazing, forages, and by-products remaining after preparation of food and drink for human consumption (e.g., maize gluten, brewers' grains).

The overall efficiencies of ME conversion into eggs, pork, milk, and beef are $0.33,0.19,0.42$, and 0.08 , respectively; for protein conversion they are $0.32,0.25,0.28$, and 0.09 . The reason why the efficiency of energy conversion to milk is greater than that for egg production can be attributed to the fact that there has, to date, been no limit to the ability of breeders to select cows to produce more and more milk, whereas hens are still restricted to the production of one egg per day. Both milk and egg production are more efficient than the intensive production of pork meat: beef production (by these measures) fails to achieve an efficiency of $10 \%$.

When energy conversion is examined in terms of competitive efficiency the picture changes. Here beef becomes as efficient as pork (or no less inefficient) and dairy farming becomes very efficient indeed. In this example, based on a typical diet fed to cows in the pasture-rich South West of England $~ 65 \% \mathrm{ME}$ is complementary and the output of food energy for human consumption is $39 \%$ greater than their demand for feed that we could eat ourselves. The ability of the dairy cow to produce 
TABLE 2 | Efficiency of energy and protein conversion in meat, milk, and egg production (from Webster, 2013).

\begin{tabular}{lcccc}
\hline & Eggs & Pork & Milk & Beef \\
\hline Production unit & 1 hen & 22 pigs & 1 cow & 1 calf \\
Support unit & 0.05 hens & 1 sow & 0.33 heifers & 1 cow \\
Output/year (kg food) & 15 & 1,300 & 8,000 & 200 \\
Food energy (MJ) & 130 & 13,000 & 28,000 & 2,500 \\
Protein (kg) & 1.65 & 208 & 264 & 32 \\
Input/year (MJ ME), total & 389 & 67,038 & 67,089 & 29,850 \\
$\quad$ "Competitive" & 351 & 53,630 & 20,127 & 10,268 \\
Input/year (kg protein), total & 5.2 & 818 & 946 & 361 \\
\multicolumn{1}{c}{ "Competitive" } & 5.0 & 736 & 236 & 108 \\
Efficiency & & & & \\
Food energy/total feed ME & 0.33 & 0.19 & 0.42 & 0.08 \\
Food energy/“competitive" & 0.35 & 0.24 & 1.39 & 0.24 \\
feed ME & & & & \\
Food protein/total feed protein & 0.32 & 0.25 & 0.28 & 0.09 \\
Food protein/“competitive" & 0.33 & 0.28 & 1.12 & 0.30 \\
feed protein & & & & \\
\hline
\end{tabular}

For each system, efficiency is described by the ratio of output to input, where output is defined by energy and protein in food for humans; inputs are described in terms of total and "competitive" intake of ME and protein, where "competitive" describes energy and protein from feed sources that could be fed directly to humans.

more food for human consumption than she eats is most marked in advanced pastoral systems as seen in New Zealand but can be achieved in fully housed systems though proper selection of complementary feeds.

Table 2 provides a powerful illustration of the fact that it possible within modern, highly productive production systems to exploit the ages-old capacity of the milch cow to contribute, rather than compete in the constant endeavour to provide good food for ourselves, both rich and poor. It would be a mistake however to assume that because it can be done, it is being done. The present state of dairy production, especially in the rich, urbanised nations, involves far too much land to grow crops like energy-rich cereals and protein-rich beans and seeds to drive dairy cows to produce more milk than is compatible with health and welfare for them, us and the planet at large.

\section{AN UNSUSTAINABLE DAIRY INDUSTRY? LIVESTOCK'S LONG SHADOW IS DESTROYING THE PLANET}

This is a fiendishly complex issue to address because, by definition, it has to embrace all of life. Attempts to achieve a comprehensive assessment of the inputs, outputs, and environmental impact of any biological or industrial process are conventionally based on the principles of life cycle analysis (LCA). The International Organisation for Standardisation (IS0 14040) defines LCA as the study of "environmental aspects and potential impacts throughout a product's life cycle from raw material acquisition through production, use, and dismissal. Environmental impacts needing consideration include resource use, human health, and environmental consequences." This is easier said than done because, as defined, it includes everything, including much that we cannot measure with any certainty and much that is subjective. Any manageable approach to an LCA will posit specific questions and select data that would seem to be most relevant to these questions. When researching the literature on resource use and environmental impact of livestock production systems, it is unsurprising therefore to discover a wide range of conclusions and opinions among authors all using valid scientific methods. This can usually be attributed to the fact that they have posed broadly similar questions but in slightly different ways. My (similarly non-comprehensive) approach to LCA in livestock production systems will focus on two of the most important issues, energy use and carbon balance, especially the net production of carbon dioxide and other greenhouse gases (GHG) especially methane.

The Food and Agriculture Organisation Report “Livestock's Long Shadow" [Food and Agriculture Organisation (FAO), 2006] catalogues in great detail the ways and the extent to which livestock production, carried out in the manner and at the scale that exists today, is creating an unsustainable burden on the living environment. Ruminants are singled out for special criticism because of their contribution to global warming through the emission of greenhouse gases (GHG), especially methane produced from fermentation of fibrous feeds in the anaerobic environment of the rumen, Methane has $\sim 25$ times the global warming potential of $\mathrm{CO}_{2}$. The LLS report considers ways to mitigate this and other environmental threats from land degradation from overgrazing, and pollution of land and water from nitrogenous wastes within current intensive systems operations at current levels of production. A grossly oversimplified take home message from their conclusions would be that it is best for the environment to eat eggs, poultry, and pork reared intensively indoors. In my opinion however, the LLS report falls short on several counts. It dodges the central issue, namely that our current problems arise not from livestock production per se, which has been an integral part of sustainable livestock production for millennia, but the current scale of livestock production, both intensive and extensive, that grossly disrupts the ecological balance. To give an obvious example: nitrogen pollution from agricultural waste is simply a case of too much fertiliser in the wrong place. LLS calculates the environmental cost of production systems in terms of global hectares of land required to produce a standard amount of different foods for humans of plant and animal origin but does not adequately take into account the differing capacity of different classes of land to produce crops, e.g., grasses vs. cereals. It does not properly account for such things as differences in the availability and therefore the value of site-specific resources, most especially, water. Problems of water supply and disposal are very different for dairy units in Israel and the west of Scotland. It does not fully consider the extent to which the effects of the emission of GHG may be offset by carbon sequestration in pasture and woodlands grazed and browsed by ruminants.

My main objection to the LLS report is that while it considers strategies for mitigating environmental costs within the context of current production methods and consumption levels, it gives 
little attention to the extent to which livestock husbandry, using appropriate species in sustainable numbers can, at best, make a positive contribution to environmental quality or, at least, greatly mitigate the costs.

\section{LIFE CYCLE ANALYSIS: ENERGY AND CARBON INPUTS, OUTPUTS, AND EMISSIONS}

Tara Garnett and her colleagues have produced an excellent overview, "Grazed and Confused" (Garnett et al., 2017) of the impact of ruminant production systems on the climate and living environment. This considers all the costs, such as GHG emissions and the nitrogen pollution of waterways but it also gives proper attention to ways in which pastoral systems, properly managed, can enhance the quality of the land. In this section, I apply the principles of partial life cycle analysis (LCA) in an attempt to quantify and compare carbon and energy exchanges in livestock production systems. The main carbon and energy inputs are feed and fuel, the main products are food (milk and meat) and "wastes" principally nitrogenous wastes in manure and greenhouse gases (GHG) released into the atmosphere.

A substantial weight of literature has accumulated in respect to net GHG emissions from livestock production systems. Net GHG emissions describe the algebraic sum of GHG production as $\mathrm{CO}_{2}$ and $\mathrm{CH}_{4}$ (mostly from animals and manure) set against carbon sequestration in land grazed by the cattle. Plants convert atmospheric $\mathrm{CO}_{2}$ into organic matter by the process of photosynthesis. Carbon is stored in the plant, above and below the ground, so long as the organic matter continues to exist, alive, or dead. Selectively felling forest trees to build houses or battleships stores $\mathrm{C}$ and gives other trees space to grow and store more. Slashing and burning the jungle to clear space for soya or palm oil production brings double jeopardy: it releases all the $\mathrm{C}$ into the atmosphere and radically reduces the future capacity for C storage. Untouched tropical rain forests, where nearly all $\mathrm{C}$ is retained within the system as organic matter sequester $\mathrm{C}$ long-term. A high proportion of $\mathrm{C}$ captured by photosynthesis is stored as organic matter within the soil. It follows that soil erosion is a major contributor to GHG production. The soil under permanent pastures of mixed grasses and clovers will store much more soil organic carbon (SOC) than arable land used for intensive production of cereals and oilseeds. However, there is a limit to the amount of $\mathrm{C}$ that can be stored so that, in time, an equilibrium is reached where net $C$ exchange between plants and atmosphere is zero.

Most of the carbon-based fuels upon which we depend today were laid down during the carboniferous era. At the beginning of this period atmospheric $\mathrm{CO}_{2}$ concentration was about 20 times the concentration of 3 parts per million ( $\mathrm{ppm}$ ) recorded at the beginning of the Anthropocene in about 1850, when human mining and consumption of fossil fuels began its it long ascent. The climate at the start of the carboniferous period was hot, wet, and most of the planet was under water. Most of the land consisted of tropical rain forest, which sequestered nearly all the carbon it captured. By the end of the carboniferous period of 60 million years atmospheric $\mathrm{CO}_{2}$ had fallen below $2 \mathrm{ppm}$. Atmospheric oxygen (currently 21\%) was over $30 \%$. Physics dictates that this period of climate instability must have ended in a catastrophe and it did: an ice age.

Table 3 presents a condensed and greatly simplified summary of data gathered by Pelletier (2008) and Pelletier et al. (2010a,b) to illustrate the application of LCA to calculate energy use and production of GHG in meat production systems in the USA. The examples include three intensive (commercial) systems, broiler chickens, pork, and feedlot beef and two more "natural" systems; "niche" pork (equivalent to organic) and beef cattle finished at pasture. The numbers are expressed to only two significant figures, given the high dependence on assumptions, even this approximation almost certainly implies a greater degree of accuracy than is warranted in terms of the absolute numbers. However, the same rules and assumption are applied throughout so the comparisons between systems may be treated with confidence. While the less intensive systems may have relied to a greater extent on complementary feed sources, fuel energy costs were significantly greater. GHG production was conspicuously greater from beef cattle finished at pasture than in feedlots. Similar conclusions may be drawn from a recent paper by Pieper et al. (2020) that estimated organic production methods for poultry and pork in Europe generate $~ 50 \%$ more GHG than intensive methods.

These comparisons should be treated with caution since they are specific to the production methods that they describe and cannot be applied worldwide. The high fuel costs for pasturefinished beef cattle in the USA reflect the high of nitrogenous fertilisers. Nevertheless, they illustrate the important point that more "natural" methods are likely to be less sustainable according to these criteria mainly because slower growing animals have a lower gross efficiency of utilisation of ME (as described above) and produce more GHG equivalents per tonne of meat for human consumption. However, this analysis, like all partial LCAs is based on limited, selected premises. It does not, for example, take into account the impact of organic farming methods on soil quality, ecological diversity including sentient wildlife or, of course, the welfare of the farmed animals.

There is a weighty volume of literature on GHG emissions from dairy cattle. Methane production is a consequence of anaerobic fermentation in the rumen, thus most of the effects of productivity and nutrition can be derived from first principles. Increasing individual milk yield decreases the amount of GHG produced per litre milk as the proportion of digestible energy directed to milk production increases with respect to that required for maintenance (see Table 2). Higher yielding dairy cows are fed a diet containing a higher proportion of starch to cellulose in the diet and this increases fermentation to propionate relative to acetate. This reduces the proportion of fermentable energy that is lost to the system in the form of "excess" protons converted to methane. These basic principles are explained in greater depth in "Understanding the Dairy Cow" (Webster, 2020). Estimates of the extent to which diet and production level can reduce GHG emissions relative to milk yield include Gerber et al. (2010). Conceptually, the most promising approach to reduction of GHG is through manipulation of the ruminal 
TABLE 3 | Life cycle analysis of energy inputs and emissions of greenhouse gases (GHG, measured as $\mathrm{CO}_{2}$ equivalents) in the production of $1 \mathrm{~kg}$ of meat in broiler chicken, pork, and beef production systems (after Pelletier, 2008; Pelletier et al., 2010a,b).

\begin{tabular}{|c|c|c|c|c|}
\hline \multirow[t]{2}{*}{ Output (1 kg meat) } & \multicolumn{3}{|c|}{ Energy use (MJ) } & \multirow{2}{*}{$\begin{array}{c}\text { GHG (kg CO} \\
\text { equivalents) }\end{array}$} \\
\hline & Feed & Fuel & Total & \\
\hline Broiler chicken & 10 & 5.0 & 15 & 1.3 \\
\hline Pork, commercial & 6.1 & 4.9 & 11 & 2.7 \\
\hline Pork, niche & 7.1 & 5.9 & 13 & 3.2 \\
\hline Beef, feedlot finished & 28 & 10 & 38 & 35 \\
\hline Beef, pasture finished & 41 & 7 & 48 & 46 \\
\hline
\end{tabular}

microbiome through diet, pharmaceuticals or possibly genetic selection. A large international study of European dairy cattle has revealed heritable differences in the rumen microbiome that should affect methane production (Wallace et al., 2019) although it has not, as yet, presented direct evidence as to the degree to which this might be achieved in practise. A very recent paper by Roque et al. (2021) has demonstrated a sustained reduction of over $60 \%$ in methane production, with a concomitant increase in hydrogen production from beef cattle as a result of feeding red seaweed Asparagopsis taxiformis, which contains significant amounts of the trihalomethane, bromoform, a known inhibitor of methane production. If it can be confirmed as both effective and safe, this holds promise.

GHG emissions associated with milk production may be compared with those associated with an equivalent production of food from simple-stomached animals. Rotz et al. (2010) using data from dairy herds in California and Pennsylvania with annual yields ranging from 5,500 to $11,000 \mathrm{~kg} /$ lactation calculated values for $\mathrm{GHG}$ production of $0.4-0.7 \mathrm{~kg} \mathrm{CO}$ equivalents per litre of milk produced. To compare these values with those in Table 3, the energy value of $1 \mathrm{~kg}$ of meat may be taken as approximately three times that of 11 of milk, so that GHG emissions from milk production correspond to $1.5-1.8 \mathrm{~kg} \mathrm{CO} 2$ equivalents per $\mathrm{kg}$ meat equivalent. By this measure, the GHG impact of milk production is intermediate between that of chicken and pork. Beef production, by any means, is extremely profligate.

Few, if any, of the soils in land currently used for agriculture are likely to be in a state of $\mathrm{C}$ equilibrium. Evidence based on measurements of soil organic $\mathrm{C}$ show that while much of the arable land used for the intensive production of cereals and oilseeds is losing carbon, European grasslands (for example) are currently sequestering $\mathrm{C}$, thus acting as a sustained $\mathrm{C}$ sink (Soussanna et al., 2010). These estimates of net $\mathrm{C}$ balance $\left(\mathrm{CO}_{2}\right.$ equivalents per $\mathrm{m}^{2}$ land) in European pastoral systems for dairy and beef production predict that the rate of $\mathrm{C}$ sequestration relative to GHG production increases with the proportion of feed that is directly grazed, so that by this measure extensive beef production from pasture-fed cattle becomes the most sustainable.

\section{EMERGY ANALYSIS}

Because all forms of life cycle analysis are partial they will inevitably lead to different conclusions according to the questions asked and the variables included in the model. To my knowledge, the closest approach to a comprehensive LCA of exchanges of energy and matter in any production system is that known as "emergy analysis," where emergy $\left(E_{\mathrm{m}}\right)$ is a measure of the amount of the original, effectively inexhaustible source of solar energy embedded at each stage of the process This concept expresses all the work processes and resources (sunlight, water, fossils fuels, minerals etc.) used in the generation of a product in terms of a common unit of measurement (Zhao and $\mathrm{Li}$, 2005). The approach is fiendishly complex, and like most LCAs carries a lot of uncertain assumptions that but it is, I believe, particularly well-suited to the assessment of the efficiency and sustainability of farming the land for food because it can identify, distinguish and quantify the renewable (R) resources of sun, soil and water embedded in farmland from non-renewable sources (NR) such as fuel, fertiliser, labour, and imported feeds (Figure 1).

In the context of food production, resources are defined as follows:

- Renewable Emergy $(\mathrm{R})=$ emergy equivalents from sustainable sources, e.g., sunlight, free water

- Unrenewable Emergy $(\mathrm{UR})=$ loss of energy from (e.g.) soil degradation

- Purchased goods and services $(F)=$ bought in feed, fuel, labour, etc.

- Yield (Y) food for human consumption

Table 4 compares yields and sustainability in different agricultural systems on the basis of the following ratios.

- $\operatorname{EYR}$ (emergy yield ratio) $=(\mathrm{R}+\mathrm{NR}+\mathrm{F}) / \mathrm{F}$. This describes the contribution of local resources (land) to product,

- $\operatorname{ELR}$ (environmental load ratio) $=(\mathrm{NR}+\mathrm{F}) / \mathrm{F}$. This describes the ratio of non-renewables to renewables in product.

- ESI (emergy sustainable index) = EYR/ELR. This becomes a measure of yield relative to environmental compatibility)

Values for EYR show that the relative contribution of local renewable resources did not differ greatly between corn production, conventional and organic pig production. The contribution of local resources was greater for dairy production, especially low-intensity dairy production in South Mali. This is consistent with the evidence presented in Table 2. The grazing of beef cattle was by far the most efficient in terms of the contribution of renewable resources. The most striking differences between the systems are revealed in column 3, ESI, the measure of yield in relation to environmental compatibility. By this measure, small scale dairy production is more sustainable than intensive production even in Brittany where a large proportion of feed comes from pasture, and extensive beef production on the Argentinian pampas outstrips all others in terms of sustainability. This may come as a surprise to urbanised critics of livestock production and beef production in general, but it would appear as an overcomplicated proof of the obvious to the gauchos of the pampas or the indigenous races of North America living in perfect symbiosis with the bison.

The LLS approach to calculating the environmental costs of agricultural systems has been based primarily on land use 


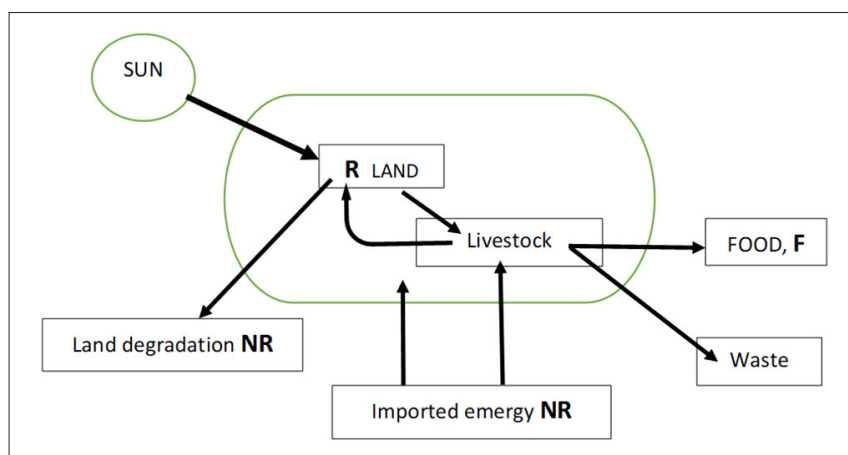

FIGURE 1 | The "Emergy" approach to the evaluation of renewable $(R)$ and non-renewable (NR) sources of energy and matter to the production of food for human consumption.

TABLE 4 | Yield and sustainability within agricultural systems assessed in terms of embedded energy ("emergy") and described by three ratios (EYR, emergy yield ratio; ELR, environmental load ratio; ESI, emergy sustainable index).

\begin{tabular}{lccc}
\hline & EYR & ELR & ESI \\
\hline Corn (USA) $^{\mathrm{a}}$ & 1.07 & 18.8 & 0.06 \\
Conventional pig (Sweden) $^{\mathrm{a}}$ & 1.04 & 22.3 & 0.05 \\
Organic pig (Sweden) $^{\mathrm{a}}$ & 1.13 & 7.80 & 0.15 \\
Intensive dairy (Brittany) $^{\mathrm{c}}$ & 1.35 & 3.25 & 0.42 \\
Extensive dairy (Mali) $^{\mathrm{c}}$ & 1.89 & 1.25 & 1.57 \\
Grazing cattle (Argentina) $^{\mathrm{b}}$ & 3.73 & 0.55 & 6.80 \\
\hline
\end{tabular}

These ratios are dimensionless. Data taken from Pereira and Ortega (2013)a , Rotolo et al. $(2007)^{b}$, and Vigne et al. (2013)c. For further explanation see text.

and concluded that the environmental cost of feeding people on beef is 10 times the cost of cereals and 40 times the cost of soya. The emergy approach yields a diametrically opposite conclusion (Table 4). By this analysis and in this example, corn and soya are the least sustainable because of their dependence on non-renewable resources of (e.g.) fertiliser and fuel (F) and degradation of soils (UR); beef from cattle grazing the pampas of Argentina are the most sustainable, both in terms of food emergy yield relative to the consumption of non-renewable resources $(\mathrm{F} / \mathrm{NR})$ and in terms of overall sustainability, defined by the Emergy Sustainable Index. I concede that the examples illustrated in Table 4 have been chosen by me to make a point. Different approaches tell different stories. However, they all point to the same two conclusions. The first is that the current demand for foods of animal origin, particularly when this involves the feeding of animals of food that we could have eaten ourselves, is unsustainable. The second conclusion is that the key to sustainable farming is to manage different land types in ways that best respect the value of the location and land as defined by its own special resources of sun, soil, and water. This, indeed, is the essence of husbandry. Nobody, I hope, would consider ploughing up the Argentine pampas; nobody, at least, who is aware of the disastrous consequences of ploughing up the North American prairies that led to the dustbowl of the "dirty thirties."
It makes good ecological sense to derive value from land best suited to pastures through the production of food of high nutritional value from animals dependent, so far as possible, on complementary feeds that we cannot eat ourselves. It makes even more ecological sense in silvopastoral systems (Chará et al., 2019) where food production is just one of several contributors to value; others being income from sustainable forestry, water management, habitat and wildlife conservation and, not least, greater carbon sequestration. These forms of good husbandry cannot, however, produce meat and milk in the quantities that the comfortable and affluent have come to expect.

\section{AN UNKIND DAIRY INDUSTRY? INTENSIVE DAIRY PRODUCTION IS INCOMPATIBLE WITH ANIMAL WELFARE}

In recent years, the most common expressions of public concern as to methods of food production have related to issues of farm animal welfare. A particular target for criticism has been the industrialisation and intensification of animal production ("factory farming") that would appear to treat the animals as commodities rather than sentient beings. This concern was given expression by Ruth Harrison in her book "Animal Machines" (Harrison, 1964), a passionate and well-researched attack on the factory farming of broiler chickens, battery hens and veal calves reared in intense confinement. This led to the Brambell Committee of Enquiry into the Welfare of Animals kept under intensive housing conditions (Brambell, 1965). They recommended that all farm animals should be given sufficient space so that they are able, without difficulty, to "stand up, lie down, turn around, groom themselves, and stretch their limbs." This recommendation became known as the Five Freedoms. A combination of public pressure, good science, and legislation has stimulated the development of improved production methods within the highly intensive systems identified by Harrison and Brambell. Egg production in the UK is now based largely on "free range" systems to the satisfaction of the general public, if not necessarily the birds. Today, one of the most serious expression of public concern is that at a time when we have freed hens from the battery cage and given them free range, the dairy industry has taken the cows out of the fields and confined them on concrete. This is an oversimplified image, but it is a powerful one that needs to be addressed.

The publication of the Brambell report led to the formation of the UK Farm Animal Welfare Advisory Committee, subsequently the Farm Animal Welfare Council (FAWC). When I was first appointed to this committee in 1979, I argued that while the five freedoms as described by Brambell were of great importance, especially in the context of the extreme confinement systems considered within their brief, there was so much more to animal welfare then just space allowance. Following much discussion, FAWC produced a concise but comprehensive summary of farm animal needs and provisions (Farm Animal Welfare Council, 2006). These are: 
- Freedom from hunger and thirst-achieved by readily accessible fresh water and a diet to maintain full health and vigour.

- Freedom from discomfort-achieved by appropriate shelter with a dry, restful lying area, and temperature within an acceptable range of tolerance.

- Freedom from pain, injury, and disease-achieved by prevention or rapid diagnosis and treatment.

- Freedom from fear-achieved by conditioning animals to their surroundings and avoiding situations that cause stress.

- Freedom to express normal patterns of behaviour-achieved by the provision of room to move, things to do and the company of their own kind.

These recommendations have stood the test of time. They are measures of outcome, now recognised as the most direct approach to the assessment of animal welfare. They are, moreover, not intended as a counsel of perfection but as a guide to good husbandry: simple enough to be memorable but comprehensive enough to be effective. Four of these five freedoms are freedoms from, and these have met with general approval. The final freedom: "to express normal patterns of behaviour" has aroused some concern. What, for example, is normal behaviour and when does normal behaviour become unacceptable? Isaac Stern expressed this well in a human context by pointing out that your freedom to swing your fist stops at the point of my nose. If I could persuade the successors to FAWC to rewrite the fifth freedom, I would re-express it simply as "freedom of choice." In practise, this implies (e.g.) freedom to select a preferred environment for rest and recreation, freedom to select and avoid contact with specific individuals in their social environment.

It is necessary to make the distinction between animal welfare and well-being. Welfare describes the physical and mental state of an animal across the whole spectrum from very good to very bad. Well-being describes a state within the range of satisfactory to good and must therefore be the aim of good husbandry. When measured strictly in terms of (short term) economics, large industrial dairy units have been an undoubted success. When measured in terms of the well-being of the animals and the land, achieved through sympathetic and sustainable husbandry, they are found to be wanting. The needs that drive the mind of the modern, highly bred, intensively fed cow are much the same as for any sentient mammal: food and water, comfort, security, and a stable social life consistent with the genetic imperative for sex. Fundamental to all these specific needs is freedom of choice: to take action to avert discomfort or threat and promote a positive sense of well-being. As we know too well, the impact of food on our state of mind is not just a matter of acquiring sufficient nutrients. So too with cows. The acts of eating and, in their case, ruminating, bring their own satisfaction. Grazing animals in the wild state have adapted to seasonal changes in food availability: lots of good grass in the summer or rainy season, much less food of much poorer quality in the winter or dry season. It is entirely natural for grazing animals to lose weight during the lean months, but provided some grazing is available, however poor the quality, they get the satisfaction of freedom to forage for what they can.
The most severe welfare problems for the dairy cow are likely to be associated with physical stresses to her physical and mental health rather than denial of behavioural expression. Relative to most farm animals she is most unlikely to suffer in consequence of having nothing to do all day. On the contrary she is worked quite extraordinarily hard. The modern dairy cow can cope in the short term with the intense metabolic demands involved in the production of $601 \mathrm{milk} /$ day (or more), coupled with the demands of consuming and digesting enough food to meet these demands. It is an inescapable fact, however, that too many succumb too soon to the long-term stresses of lactation, in particular, the production diseases such as rumen acidosis, ketosis and environmental mastitis and lameness that are, by definition, linked to the methods employed in the breeding, feeding, and housing of cows to produce large quantities of milk and therefore, by definition, our fault.

Table 5 presents a brief summary of potential welfare abuses that may occur in dairy systems. For the most part it is based on the template laid down by the five freedoms, but includes a further stress, namely that of exhaustion arising from failure to cope, in the long term, with the exacting physical demands of lactation. For the dairy cow, exhaustion is probably the biggest problem of all. It describes a cow broken down in body, and probably in spirit, through a combination of stresses associated with nutrition, housing, hygiene, and management exacerbated in many cases by breeding programmes that have overemphasised productivity at the expense of robust good health. Too many infertile, emaciated, or chronically lame cows are culled prematurely because they are no longer making a productive contribution to the enterprise. This is not only an abuse of welfare but also a terrible waste since a dairy cow needs to complete at least four lactations to recoup the cost of rearing her as a heifer until she delivers her first calf and enters the milking herd (Webster, 2020).

The most common breed of dairy cow in intensive systems is the Holstein. During the period 2002-2014, average lactation yields in UK Holsteins increased by $21 \%$ from 7,637 to $9,239 \mathrm{~kg} / /$ head (AHDB, 2018). Within "elite" dairy herds in the USA average lactation yields in excess of $11,000 \mathrm{~kg}$ are commonplace. These increases have been achieved through a combination of selection strategies heavily weighted toward increased production of milk solids and developments in nutrition designed to support the high metabolic demands of lactation within the constraints of appetite. In simple terms, this involves increasing the ratio of cereals, where the main energy source is starch, and protein-rich oilseeds (e.g., soya, rapeseed) to forages (fresh and conserved grasses) where the main energy source is digestible fibre. Whatever their genetic potential, it is only possible to achieve these high yields if the cows are confined and forage intake is restricted. This policy inevitably presents threats to health and welfare.

Cows are not motivated to eat by a desire to reward the farmer with as much milk as possible, but by the desire to attain a feeling of comfortable satiety. Their capacity to take in food, especially fibrous food essential for healthy digestion, is constrained by the rate at which this food can be fermented in the rumen. Selection for increased yield increases the probability that they 
TABLE 5 | Abuses of the five freedoms that can arise through systematic failures in the provision of good husbandry.

\begin{tabular}{ll}
\hline Hunger & Nutrition fails to meet the metabolic demands of lactation \\
Chronic discomfort & Ruminal indigestion \\
& Poorly designed cubicles, inadequate bedding \\
Pain and injury & Claw disorders (sole ulcer, white line disease) \\
& Digital dermatitis \\
& Damaged knees and hocks \\
Disease & Mastitis, ketosis, \\
Fear and stress & Rough handling, bullying, separation from calf \\
Lack of choice & Zero grazing, inadequate rest time \\
Exhaustion & Emaciation, infertility
\end{tabular}

will be unable to meet their metabolic demand for nutrients to sustain lactation and body condition within the limit of appetite set by the capacity and rate of digestion within the rumen. If they cannot eat enough to meet their metabolic demands, they will experience a sense of chronic metabolic hunger. To increase nutrient intake within the constraints of gut fill it is necessary to increase fermentation rate within the rumen by increasing the proportion of rapidly digestible starch to slowly digestible fibre. This increases the risk of ruminal acidosis, which is, at least uncomfortable and, in severe cases can lead to severe malaise and even death (Vigne et al., 2013). Many high yielding cows can simultaneously suffer from chronic hunger and the discomfort of ruminal indigestion. This is not a good feeling.

Cows' need for comfort is greatly influenced by their size and shape. The modern Holstein weighs over $700 \mathrm{~kg}$ and has prominent joints, especially knees and hocks. For comfort they need to lie down on pasture or a deformable bed of straw or sand. Concrete does not feel good. Cows are motivated to lie down to rest for about 11 hours per day (Norring and Valros, 2016). There comes a point where the need to lie down overrides the need to eat. In many intensive units high yielding dairy cows are milked three times daily, having queued to enter the milking parlour. They are also compelled to eat for at least $8 \mathrm{~h}$ to meet their nutrient demands. With so much to do, the time to lie at rest will be much less that they would wish.

Cows, like all sentient animals, are motivated by curiosity and caution. Curiosity is a powerful motivator in early life as calves seek to gather useful information. In later life, in a stable environment, caution becomes the wiser approach to ensuring a sense of security. Most cows in stable groups establish a stable hierarchy, through the exchange of social signals that usually avoid physical conflict. In houses where each cow has access to an individual cubicle it is normal for each to use the same cubicle every time. Overworked by the demands of lactation, they opt for the quiet life. However, they do retain their curiosity. If you wish to be entirely surrounded by curious cows, lie down in a field and the rest will follow. Horizontal, we present no threat and become interesting.

Whether on the family farm or in large intensive units, the dairy cow is a valuable individual and will be given individual attention. Despite this, dairy cows are at high risk of three major health problems, infertility, mastitis, and lameness. These conditions are known as production diseases, a phrase that concedes that they are largely our fault. Pryce et al. (1997) explored the genotypic and phenotypic links between selection for increase milk yield and the incidence of these three conditions. At that time there was a significant genotypic correlation between milk yield and all three. In the case of infertility and mastitis, there was no significant phenotypic link, which indicates that farmers were able to offset genotypic deterioration in these traits through improvements in management. In the case of lameness both genetic and phenotypic correlations were significant, which suggests that farmers were failing to hold the line. In recognition of the genetic link between selection policies heavily weighted toward increased yield, breeding companies have reformulated their selection indices to give increased emphasis to traits defined as robust as measured by an increase in productive life span (De Mello et al., 2014). In the selection index currently used by the UK Independent Dairy Breeding Company nearly 70\% of traits are now based on measures of fitness, longevity and good welfare. The impact of selection for this set of traits on the progeny of tested bulls is integrated in the form of the Profitable Lifetime Index. ${ }^{1}$ However, individual farmers can select bulls to suit individual cows and their individual systems by giving individual attention to specific traits related to resistance to the main production diseases: fertility, body condition, locomotion, and somatic cell counts (SCC), for resistance to mastitis.

There is, at present, no evidence to suggest that the incidence of production diseases is greater in large intensive units than on the traditional family farm. The incidence of infertility is linked to poor body condition, itself a consequence imbalance between the metabolic needs of lactation and the capacity of the cow to ingest and digest feed. While digestive disorders, especially rumen acidosis, are a major threat to the welfare of dairy cows, improvements in understanding of ruminant nutrition and the application of this new knowledge to the formulation of total mixed rations have done much to reduce the risks attached to the selection and management of high genetic merit cows to produce prodigious quantities of milk. The risk of physical discomfort, pain and injury in dairy cows attributable to poor housing and inadequate control of lameness is high. However, once again, there is no convincing evidence to suggest that these problems are worse in large, intensive units where cows are confined throughout lactation than in small family farms, where cows are at pasture during the summer. Indeed, the physical environment within large, new, expensive dairy units can often present a lower risk of injury than on the traditional, old, undercapitalised family farm.

There are some practises that we inflict on cows entirely for our benefit, in full knowledge that they conflict with how they would naturally perform to promote a sense of well-being. The top three, in ascending order of importance, are:

- Tethering cows throughout the time they are housed

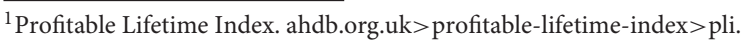


- Keeping cows permanently housed, without access to pasture

- Removing calves from their mothers shortly after birth.

In many small rural communities it has been traditional to keep dairy cows outdoors all summer on lush pastures, like Alpine meadows, then bring them in for the winter and tether them in tie-barns where they will be fed, watered, and milked until turn-out in the spring. This practise has given rise to concern mainly on the grounds that it denies freedom of movement and opportunities for a social life. I know of no evidence that cows display signs of distress associated with prolonged tethering, although passing the winter group-housed in a barn with deep clean straw and access to an outside yard would undoubtedly be better. Some free-stall houses with insufficient, poorly bedded cubicles, and filthy passageways can be worse than tie-stalls. In any event, tie-stalls are incompatible with modern milking systems and will, I predict, gradually fade away.

In a few areas, such as UK, Ireland, and New Zealand people are accustomed to seeing dairy cows outdoors at grass during the summer, so assume this to be the natural state. However, this is becoming the exception through most of the developed world where the majority of lactating dairy cows are kept off pasture throughout their working life. The trend in commercial dairy production, world-wide, is toward industrialised units of 1,000 or more very high-yielding cows. In order to sustain these high yields, the cows are housed throughout lactation and given continuous access to a ration that ensures they take in far more nutrients than they could possibly derive from grazing at pasture because nutrient density of the ration is higher and the feed can be consumed more rapidly. Confinement also keeps the cows close enough to the milking parlour to permit thrice-daily milking or, increasingly, the use of a robot milking machine that they can enter of their own free will. This offers freedom of choice. However, robot milking machines are only practicable when cows are permanently housed. Mature cows do not appear to be strongly motivated to enter the milking parlour simply to relieve discomfort to their distended udders (Prescott et al., 1998). They need a food stimulus to attract them in from pasture. The attractions of pasture can be greater than the attractions of the robot milker, even when feed is on offer in the parlour. In consequence they visit the robot less often and milk yield falls. This makes it progressively easier for the cow to meet her metabolic needs from pasture so increases her preference to stay outdoors. Her welfare will improve but her productivity will fall. In some large, intensive units cows are confined throughout lactation but given a period of recreation on pasture for a few weeks during the dry period when they have completed their lactation and await their next calf.

Pasture provides an excellent source of nutrients in the form of fresh and conserved grasses and clovers. Moreover, when the weather is fine, pasture is an ideal environment for dairy cows. Here they can do much as they please: take in food, excrete urine and faeces, exercise, rest, enjoy fresh air and space, socialise and satisfy their curiosity. There is however a conflict between the use of pasture as a recreation area and the need to maximise its potential as a source of high-quality feed. Once the first flush of spring grass is over, most of the best grasslands are harvested for silage. For much of the so-called grazing season cows may be turned out onto "sacrifice" pastures that provide little nutrition but all the other amenities. In these circumstances pasture is serving only as a recreation area. The most cow-friendly farm I have ever seen was in the forested foothills of the Pyrenees in northern Spain. Cows could choose to roam in comfort and security among the trees, or rest in well-bedded kennels. There was little of nutritional value in the forest but much of interest. Nutrition, including freshly cut grass in season was provided at a feeding station close to the milking parlour. This "zerograzing" system came as close as possible to meeting all their day-to-day needs, but it was exceptional. Ideally, cows should have freedom of choice to go outdoors, when they wish, where there is space, cool fresh air, and a comfortable place to rest. Cows are, undoubtedly highly motivated to graze fresh grass and I am always moved to watch the scenes of excitement when they are first turned out in spring but I cannot find strong evidence to indicate that they suffer from the inability to graze per se.

Our most extreme disturbance to the emotional state and natural behaviour of dairy cows is the policy of removing their calves shortly after birth, partly for ease of management but mainly to maximise income from sale of milk. It is difficult to estimate the possible magnitude of this practise in scientific terms. Comprehensive reviews of the literature relating to the effects of early separation on the behaviour (Meagher et al., 2019) and health (Beaver et al., 2019) of cows and calves reveal little of significance. We have little option but to consider the practise within the context of the natural behaviour of cow and calf.

Whether in the wild, or out-of-doors on the farm, the natural behaviour of the dairy cow at parturition is to separate from the herd and give birth in what she thinks will be a safe spot, for example, close to a hedge. Having licked the calf into shape and given it a first meal, she leaves it and returns to the herd; instructing it, in effect, to lie still and unnoticed until she returns to give it another drink. This behaviour is hard wired and has survival value. After a few days, when the calf has become active and can move as well as its mother, it will join the herd, spending much of the time with other calves, because they are more interesting, visiting its mother perhaps 4-6 times daily for a feed and usually resting with her at night. It is natural for cows and their calves to spend a long time apart, but both show signs of distress if not together at mealtimes. A few farmers separate cow and calf but allow the calf to join its mother twice daily to take a modest feed before the rest of the milk goes into the machine. This system appears to be acceptable to both mother and calf. Many domesticated water buffalo, e.g., in India, will not permit themselves to be milked unless their calf is present.

While I believe that the twice-daily access system is a reasonable approach to sympathetic husbandry, it is likely to remain a minority pursuit. What then is the least-worst approach to early weaning? In this context, the French word sevrage is more accurate. At present, the most common practise is to separate the calf within $24 \mathrm{~h}$ of birth. On some traditional dairy farms, calves will be left with their mothers for 2-3 weeks to ensure they get the full benefits of mother's milk. However, weaning after 3 weeks undoubtedly causes more distress to both cow and calf 
than weaning shortly after birth. Early weaning is an unpleasant business but, in the words of the murderous Macbeth "when 'tis done, it were well it were done quickly."

\section{THE POISON IS IN THE DOSE}

I have, so far, sought to address major sources of criticism of modern dairy practise arising from both the concerned general public and those with professional knowledge of the industry. In each case, I start from the premise that there is a case to answer then proceed to examination of the evidence. Some is taken from new science, and here I have included a small number of citations, as an introduction to further reading. However, most of my argument has been based on established scientific principles of nutrition, physiology, genetics, and behaviour, together with equally well-established practical principles of good husbandry. Selected references to original scientific communications would, I believe, add little to this element of my argument. Many points are explored in greater detail in the latest edition of "Understanding the Dairy Cow" (Webster, 2020).

The common theme that emerges from examination of this critique of the dairy industry is that problems are almost entirely problems of scale: "the poison is in the dose." Most of us who can, consume too much meat and milk for our own health and for the health of the planet. A significant reduction in our consumption of food from animals, especially those that are largely dependent on food that we could eat ourselves (e.g., cereals and proteinaceous beans and seeds), would greatly reduce the amount of land needed for growing crops and thereby improve the long-term quality and sustainability of the land through reforestation, rewilding and carbon sequestration, especially within the soil. A diet and lifestyle that excludes all food and other products of animal origin may be ethically justified within a framework that considers ethics only within the human dimension but becomes difficult to justify when considered within the broader context of efficient use of resource and sustainable management of the ecosystem, especially the huge areas of natural grasslands and savannah (grasses, trees and shrubs). At present, much of this land has been degraded by overgrazing. However, well-managed pastoral and silvopastoral systems can improve the quality of the land as measured in terms of plant and animal diversity, soil quality, carbon sequestration and amenity value. Conservation grazing, using a stable population of suitably adapted ruminants involving a sensible programme of population control, can be an essential to this approach to sustainable land management, sustained, in part, through a policy of controlled culling of animals for human consumption. This can be more profitable and more humane than leaving them out to starve or be eaten by wolves.

Pollution of the soil and water with agricultural wastes from intensive livestock units is, I repeat, a case of too much potentially valuable fertiliser in the wrong place. In the case of pollution with nitrogenous materials, much of this arises from a non-renewable resource bought into the unit in the form of fertilisers and high-protein feed supplements, and disposed of at too high a concentration, too close to the factory farm. The core principle of organic farming is to ensure the maximum possible contribution, recycling, and conservation of resources derived from within the farm itself. In the short term, this can never generate yields to compare with production units that depend wholly or in large part on purchased, non-renewable resources. In the long term however, they offer the only truly sustainable option.

Currently, methane production from ruminants is estimated to contribute $\sim 10 \%$ to the planetary production of greenhouse gases (GHG). The current cattle population of the USA is (very approximately) 100 million animals, of which about 40 million are adult cows. It has been estimated that in the seventeenth century, before the arrival of Europeans bent on slaughter, the bison population of North America was $\sim 60$ million. After adjusting for the fact that grazing animals produce more methane per unit of digestible energy than cattle fed on high concentrate rations, one can make a rough estimate that methane production from ruminants in North America is only about 20-25\% higher than it was 300 years ago. If, as seems inevitable, we are compelled to reduce world production and consumption of meat and milk by $20-25 \%$, then levels of methane production from ruminants should return to pre-industrial levels.

Moreover, as explained earlier, this assertion fails to consider the extent to which this effect may be mitigated by carbon sequestration, especially in situations where ruminants derive their sustenance entirely (or almost entirely) from permanent pastures. Well-managed grasslands can constitute a significant carbon sink, the extent of carbon sequestration depending on factors such as the intensity of grazing and the balance between grasses and legumes. The true impact of ruminants on climate change through the net production of greenhouse gases can only be determined by life-cycle analysis of the production and sequestration of greenhouse gases $\left(\mathrm{CO}_{2}\right.$ and $\left.\mathrm{CH}_{4}\right)$ in different systems. While it is the case that estimates based on life-cycle analysis show that all current dairy systems make a positive net contribution to greenhouse gas production, it is far less than estimates based on $\mathrm{CH}_{4}$ emissions alone and least of all when the contribution of pasture to the overall diet is greatest. Extensive systems of beef production from pasture are likely to be GHG neutral (as would have been the herds of prairie bison).

\section{OPPORTUNITIES FOR CHANGE}

We cannot escape the fact that our present rate of consumption of foods of animal origin is unsustainable. It is in our own interests to embark now on a strategic programme of change in livestock farming with similar aims to our current long-term programme to work toward net carbon balance. Indeed, the two strategies overlap within the same overriding, essential need: to restore the balance of nature. Unless we make some relatively painless changes to our lifestyle now, our children will have far more uncomfortable changes thrust upon them in the future. However, we will not (in sufficient numbers) do this of our own free will while the status quo remains so comfortable. We must be made 
to change. This will require a balanced menu of attractive carrots and humane applications of the stick.

This is a big subject. My brief is restricted to changes that can be achieved within the dairy industry. Any strategy for change must take account of, and give proper respect to, the needs of the consumers, the farmers, the environment and the cows. It must also plan for an absolute reduction in global milk production. This is counter to current economic thinking that continuous growth is essential to economic stability. In biological terms, this premise is, of course, an absurdity; well-expressed by David Attenborough who said "the only people who believe in continuous growth are economists and lunatics."

The prospect of new, greener, kinder approaches to milk production becomes more realistic when we reflect that the hyper intensive dairy industry in the affluent industrialised regions of today's world is not the norm, but a product of the last 50 years, an intense but unsustainable spike in the balance of nature. I rephrase my words at the outset: For most of recorded history the role of the family cow was to provide milk, work, fertiliser, fuel, clothing, and the occasional fatted calf for special occasions, while sustained by fibrous feeds that the family could not digest for themselves, usually from land that the family did not own. She was not competing with the family for food; she was an essential contributor to the harvest and she was valued accordingly. I am not suggesting that we should return to "the good old days," not least because for most people dependent on subsistence agriculture then and now throughout most of the underdeveloped world, days were and are not that good. What I am saying is that any future developments should incorporate all that is of value in new knowledge and technology but also ascribe proper value to the sources of this wealth, the cows and the land. Respect for cows may be a moral issue, respect for the land is a matter of survival. These principles apply equally throughout the dairy industry from the highly intensive $>1,000$-cow dairy units of Wisconsin to the dairy syndicates of India receiving and processing milk from multiple small famers, each with perhaps 2-5 cows.

Increased sustainability of food production systems depends on increasing the contribution of renewable as distinct from non-renewable resources. I have briefly described an elegant and comprehensive way to quantify these by way of "emergy" analysis (Figure 1). This makes it possible to estimate (with considerable uncertainty) an "Energy Sustainable Index" (ESI) for different systems. Table 4 turns current agricultural economics on its head. Corn (maize), which ranks highest in terms of productivity (yield/ha) becomes the worst when measured in terms of sustainability. Beef cattle, sustained entirely from pasture are the least productive, but most sustainable. This is an extreme illustration of a general truth, which is that increased sustainability of food production from animals must be accompanied by a reduction in production. This has to be a good thing for the health and welfare of ourselves (the consumers), the cows and the living environment. It will however, cost more money and this may present serious problems for farmers and consumers, particularly those with least money to spend.

I have the good fortune to live in Somerset, classic cow country from time immemorial. The word "Somerset" describes the land of the Summer people, who brought their cattle down each summer to graze the coastal marshes, flooded in winter, but a reliable source of quality pasture throughout the driest of summers. Table 2, which shows that dairy cows can produce $40 \%$ more food energy for human consumption that they consume in terms of food that we could eat ourselves, is based on data taken from the feeding programme of my immediate neighbour, who grows over $60 \%$ of the feed for his cows on farm. The largest producers of yoghourt in the UK farm the Somerset grasslands to organic standards. A central tenet of their policy has not been to select their cows for milk production per se but for milk production from pasture, which inevitably means less milk per cow.

The dairy industry in New Zealand is almost entirely pasture based but presents cows (and their calves) many of the stresses associated with the most intensive indoor systems. Cows are expected to calve at 12-month intervals to synchronise peak lactation and peak grass supply. In 1960, 60\% of the dairy herd were Jerseys. Thereafter genetic selection almost entirely favoured Holsteins based on criteria similar to those applied to Holsteins in the USA bred to live in barns. A selection index heavily weighted for milk yield was, in this environment, incompatible with maintaining high fertility at 12 month intervals. For some time, there was a policy to abort cows that were slow to conceive. Thankfully, this policy has largely been abandoned, reflecting a selection policy designed to place greater emphasis on fertility (Lembeye et al., 2021).

While the production of milk from grazed pasture can be an excellent example of good husbandry; farming the land for what it is best equipped to provide and selecting the cows best suited to this policy, it represents a small and diminishing sector of the international dairy industry. The greater challenge is to apply the principles of sustainability to the vast numbers of cows kept on large, industrialised units with little, if any access to pasture. In theory, it would be possible to provide a high proportion of feed from local renewable resources (e.g., organic grassland). In practise, short-term economics dictate that most producers will rely to a large extent on bought-in feed and fertiliser (NR). This leads to problems of waste disposal, especially $\mathrm{N}$ and $\mathrm{P}$. The European Union has issued directives to limit emissions of $\mathrm{N}$ and $\mathrm{P}$, reinforced by levies for exceeding defined limits. Dutch dairy farmers have responded to these directives by reducing the application of $\mathrm{N}$ and $\mathrm{P}$ fertilisers to grasslands and, in some cases reducing protein in concentrate rations. This application of the stick has reduced pollution problems at the "cost" of a small reduction in productivity as measured by lactation yield (Van Grinsven et al., 2016).

There are, at least in theory, several approaches to the reduction of methane emissions from rumen fermentation. As explained earlier, methane emission relative to milk production falls with increased milk yield and increased intake of starchy concentrates. Moreover, when cows are housed and fed on a formulated total mixed ration there is greater potential to reduce methane emissions through control of diet and manipulation of the ruminal microbiome (Bulumulla et al., 2017). It is also possible to reduce total emissions of GHG and other pollutants such as nitrates through improved manure management. Llonch 
et al. (2017) have reviewed the health and welfare consequences of alternative approaches. The bulk of the evidence suggests that methane production can be reduced by up to $50 \%$ by a combination of diet and the use of drugs such as ionophores. The very recent paper by Roque et al. (2021) suggests that natural sources of a trihalomethane (bromoform) may be more effective. However, any manipulation of the rumen population designed to depart from the "normal" carries the risk of reducing fermentation rate and thereby feed intake. The demonstration of heritable genetic differences in the rumen microbiome offers an alternative prospect of selecting a population of low methane producers (Wallace et al., 2019). It remains to be seen how this prospect may compare with the effects of diet and feed additives in terms of its potential impact on the environment, productivity, and welfare.

A particularly attractive solution to problems of methane emissions (and much else) is the development of Silvo-pastoral systems where cattle graze, browse, and relax within a parkland area of pasture, shrubs, and trees that act as shelters and carbon sinks (Cubbage et al., 2012; Vigne et al., 2013). In Brazil, for example, there are highly successful commercial silvopastoral systems (both beef and dairy), that generate income both from the cattle and the sale of tree biomass. A different but equally attractive example of ecologically sound diversification can be seen in the cork-oak parklands of Portugal grazed by the beautiful Mertolenga cattle. Income is generated from the sale of beef, corks for high-quality wines and tourists wishing to enjoy the natural environment. The cattle can select what to graze or browse and where to lie to their satisfaction (e.g., in sun or shade). In all but the most severe weather, they are comfortable and, above all, have freedom of choice.

These examples show that there are ways to produce green milk and meat from contented cows, but they are the exception. The more important question is how may we aspire to these aims within the great majority of industrialised high input/high output systems. Short-term economics that measure success simply in terms of profit margins will always favour the most intensive system. Some control over this can be achieved through imposition of penalties for environmental pollution, but greater progress can be achieved through a judicious selection of carrots. Happily, in recent years, public pressure for higher animal welfare standards and political pressure to mitigate environmental costs have started to move things in the right direction. One approach is to farm to organic standards set by the Soil Association ${ }^{2}$ that require (e.g.) no use of artificial fertilisers and that a minimum of $60 \%$ of the ration should be based on fresh or conserved pasture. At present only $4 \%$ of dairy farms in the UK are organic. However, these farms are competing successfully because there is a niche market for organic milk. As I write, the average price for organic milk is about $40 \mathrm{p} / \mathrm{l}$; conventional milk about $30 \mathrm{p} / \mathrm{l}$. By contrast, oat milk, with a much lower nutritional value retails at about $£ 1.40 / 1$.

\footnotetext{
${ }^{2}$ Soil Association Organic Standards. www.soilassociation.org.
}

Public demand for high standards of cow welfare has had a greater impact than the demand for organic milk, probably because the financial cost to consumers has been relatively small. Thanks largely to public pressure for higher welfare standards, most dairy herds in UK now operate according the standards set by a Welfare Quality Assurance Scheme. Examples include the Red Tractor Scheme, RSPCA Assured (formerly Freedom Foods) and those established by competing supermarkets. All require monitoring by independent assessors to ensure compliance with the standards of the scheme. This is not the place to argue in detail about the relative merits of the different schemes. However, those operated by the supermarkets have had the largest uptake in terms of milk sold. This is an example of how competition within the free market can be a force for change. Supermarkets recognise a public demand for higher animal welfare standards, albeit somewhat price-elastic, and compete by including on their shelves products of animal origin, like milk and free-range eggs produced according to quality-assured high welfare standards. The aim is to attract customers to this supermarket on the basis of these assurances who then do the bulk of their food shopping in the same store. This allows the supermarket to pay a higher price for quality-assured milk, without significant effect on their overall profit margins.

While the incentives and penalties considered above are steps in the right direction, they fall far short of the changes needed to achieve the aim of "green milk," where "green" may be defined by net zero GHG emissions. This should be incorporated into the aims of the International Climate Commission and lead to government action enforced by law. The departure of the UK from the European Union has created the opportunity to rethink the agricultural support policy. It has been proposed that all agricultural subsidies should be redirected from support for food production toward support for public goods such as long-term management of soil and water resources, carbon sequestration, diversity of habitat and wildlife conservation. This would recognise that farmers are, by default, not only food suppliers but the most important direct custodians of the natural environment. This is a lofty aspiration. It remains to be seen how close we shall get to meeting this aim and whether the money involved will be sufficient to achieve significant improvement in environmental quality without bankrupting farmers in the process. In the specific context of green milk from contented cows, it has the potential to address two of the cows' greatest challenges, overwork and lack of choice. The stress of overwork can be reduced through feeding and breeding strategies designed to achieve the more robust cow, producing less milk per lactation, but with a longer, more comfortable, productive life. The problem of lack of choice can be addressed by ensuring that in any policy of environmental enrichment for the public good, the word "public" should embrace the cows.

\section{AUTHOR CONTRIBUTIONS}

JW performed the literature review, analysed and interpreted the findings, and wrote the manuscript. 


\section{REFERENCES}

AHDB (2018). Dairy Performance Results 2017-2018. Available online at: https:// ahdb.org.uk/knowledge-library

Beaver, A., Meagher, R. K., van Keyserlingk, M. A. G., and Weary, D. M. (2019), A systematic review of the effects of early separation on cow and calf health. J. Dairy Sci. 102, 5784-5810. doi: 10.3168/jds.2018-15603

Brambell, F. W. R. (1965). Report of Technical Committee to Enquire into the Welfare of Animals Kept Under Intensive Husbandry Systems. HMSO, London.

Bulumulla, A., Zhou, M., and Guan, L. (2017). "The rumen microbiota and its role in dairy cow production and health," in Achieving Sustainable Production fof Milk, Vol. 3 Dairy Herd Management and Welfare, ed J. Webster (Cambridge: Burleigh Dodds), 157-180. doi: 10.19103/AS.2016.0006.08

Chará, J., Reyes, E., Peri, P., Otte, J., Arce, E., and Schneider, F. (2019). Silvopastoral Systems and their Contribution to Improved Resource Use and Sustainable Development Goals: Evidence From Latin America. FAO, CIPAV and Agri Benchmark, Cali. p. 60.

Compassion in World Farming (CIWF) (2020). Statistics: Dairy Cows. Available online at: https://www.ciwf.org.uk/

Cubbage, F., Balmelli, G., Bussoni, A., Noellemeyer, E., Pachas, A. N., Fassola, H., et al. (2012). Comparing silvopastoral systems in eight regions of the world. Agroforestry Syst. 86, 303-314. doi: 10.1007/s10457-012-9482-z

De Mello, F., Kern, E. L., and Bretas, A. (2014). Longevity in Dairy Cattle Advances in Dairy Research 2014. 1-3. doi: 10.4172/2329-888X.1000126

Farm Animal Welfare Council (2006). Second Report on Priorities for Research and Development. Tolworth: HMSO Publications.

Food and Agriculture Organisation (FAO) (2006). Livestock's Long Shadow, Environmental Issues and Options. Available online at: http://www.fao.org/ publications

Food and Agriculture Organisation (FAO) (2020). The State of Food Security and Nutrition in the World 2020. Available online at: https://www.fao.org/state- offood security-nutrition/en/

Garnett, T., Godde, C., Muller, A., Röös, E., Smith, P., Boer, I., et al. (2017). Grazed and Confused. Oxford: Food Climate Research Network.

Gerber, P., Vellinga, T., and Opio, C. (2010). Productivity gains and greenhouse gas emissions intensity in dairy systems. Livestock Sci. 139, 100-108. doi: 10.1016/j.livsci.2011.03.012

Harrison, R. (1964). Animal Machines. London: Smart.

Lembeye, F., Lopez-Villalobos, N., and Burke, J. L. (2021). Selection scheme designs for dairy cattle milked once daily in New Zealand: a deterministic approach. New Zeal. J. Agric. Res. 64, 127-142. doi: $10.1080 / 00288233.2020 .1852580$

Llonch, P., Haskell, M. J., Dewhurst, R. J., and Turner, S. P. (2017). Current available strategies to integrate greenhouse gas emissions in livestock systems: an animal welfare perspective. Animal 11, 274-284. doi: 10.1017/S1751731116001440

Meagher, R. K., Beaver, A., Weary, D. M., and van Keyserlingk, M. A. G. (2019). A systematic review of the effects of prolonged cow-calf contact on behaviour, welfare and productivity. J Dairy Sci. 102, 5765-5783. doi: $10.3168 /$ jds.2018-16021

Norring, M., and Valros, A. (2016). The effect of lying motivation on cow behavior. Appl. Animal Behav. Sci. 176, 1-5. doi: 10.1016/j.applanim.2015. 11.022

Pelletier, N. (2008). Environmental performance in the US broiler poultry sector: life cycle energy use and greenhouse gas, ozone depleting, acidifying and eutrophying emissions. Agric. Syst. 98, 67-83. doi: 10.1016/j.agsy.2008. 03.007

Pelletier, N., Lammers, P., Stender, D., and Pirog, R. (2010a). Life cycle assessment of high and low profitability commodity and niche production systems in the upper mid-western United States. Agric. Syst. 103, 599-608. doi: 10.1016/j.agsy.2010.07.001
Pelletier, N., Pirog, R., and Rasmussen, R. (2010b). Comparative life cycle environmental impact of three beef production strategies in in the upper mid-western United States. Agricultural Systems 103, 380-389. doi: 10.1016/j.agsy.2010.03.009

Pereira, L., and Ortega, E. (2013). A modified footprint method: the case study of Brazil. Ecol. Indicators 16, 113-127. doi: 10.1016/j.ecolind.2011.06.016

Pieper, M., Michalke, A., and Gaugler, T. (2020). Calculation of external climat costs for food highlights inadequate pricing of animal products. Nat. Commun. 11, 1-13. doi: 10.1038/s41467-020-19474-6

Pollan, M. (2008). In Defence of Food: An Eater's Manifesto. New York, NY: Goodyear.

Prescott, N. B., Mottram, T. T., and Webster, A. J. F. (1998). Effect of food type and location on the attendance to an automatic milking system by dairy cows and the effect of feeding during milking on their behaviour and milking characteristics. Anim. Sci. 67, 183-193. doi: 10.1017/S1357729800009942

Pryce, J. E., Veerkamp, R. F., Thompson, R., Hill, W. G., and Simm, G. (1997). Genetic aspects of common health disorders and measures of fertility in Holstein-Friesian cattle. Anim. Sci. 65, 353-360. doi: $10.1017 /$ S1357729800008559

Roque, B. M., Venegas, M., Kinley, R. D., de Nys, R., Duarte, T. L., Yang, X., et al. (2021). Redseaweed (Asparagopsis taxiformis) supplementation reduces enteric methane by over 80 percent in beef steers. PLoS ONE 16:e0247820. doi: 10.1371/journal.pone.0247820

Rotolo, G. C., Rydberg, T., and Liebline, G. (2007). Emergy evaluation of grazing cattle in Argentina's Pampas. Agric. Ecosyst. Environ. 119, 383-395. doi: 10.1016/j.agee.2006.08.011

Rotz, C. A., Montes, F., and Chianese, D. S. (2010). The carbon footprint of dairy production systems through partial life cycle assessment. J. Dairy Sci. 93, 1266-1282. doi: 10.3168/jds.2009-2162

Soussanna, J. F., Tallec, T., and Blanfort, V. (2010). Mitigating the greenhouse gas balance of ruminant production systems through carbon sequestration in grasslands. Animal 4, 334-340. doi: 10.1017/S1751731109990784

Van Grinsven, H. J. M., Tiktak, A., and Rougoor, C. W. (2016). Evaluation of the Dutch implementation of the nitrates directive, the water framework directive and the national emissions ceiling directive. NJAS Wageningen. J. Life Sci. 78, 69-84. doi: 10.1016/j.njas.2016.03.010

Vigne, M., Peyraud, J. L., Leconte, P., and Corson, M. S. (2013). Emergy evaluation of contrasting dairy systems at multiple levels. J. Environ. Manage. 129, 44-53. doi: 10.1016/j.jenvman.2013.05.015

Wallace, R. J., Sasson, G., Garnsworthy, P. C., Tapio, I., Gregson, E., Bani, P., et al. (2019). A heritable subset of the core rumen microbiome dictates dairy cow productivity and emissions. Sci. Adv. 5:eaav8391. doi: 10.1126/sciadv.aav8391

Webster, J. (2013). Animal Husbandry Regained: The Place of Farm Animals in Sustainable Agriculture. Routledge: Earthscan.

Webster, J. (2016). Animal Husbandry Regained: The Place of Farm Animals in Sustainable Agriculture. Routledge: Earthscan.

Webster, J. (2020). Understanding the Dairy Cow. Oxford: Wiley.

Zhao, S., and Li, W. (2005). A modified method of ecological footprint calculation and its application. Ecol. Modell. 185, 65-75. doi: 10.1016/j.ecolmodel.2004.11.016

Conflict of Interest: The author declares that the research was conducted in the absence of any commercial or financial relationships that could be construed as a potential conflict of interest.

Copyright (c) 2021 Webster. This is an open-access article distributed under the terms of the Creative Commons Attribution License (CC BY). The use, distribution or reproduction in other forums is permitted, provided the original author(s) and the copyright owner(s) are credited and that the original publication in this journal is cited, in accordance with accepted academic practice. No use, distribution or reproduction is permitted which does not comply with these terms. 